Navigation Physics 1(1)(2019)
Navigation Physics
Journal of Physics Education

\title{
Rancang Bangun Alat Pembuka Pintu Portal Berbasis Arduino Menggunakan Smartphone
}

\author{
Achmad Haris Afandi ${ }^{1 *}$, Putri Anbar Ghalia ${ }^{2}$, Kistiani $^{3}$, Indri Rahma Sari ${ }^{4}$, dan Sri Aswaidar Miza ${ }^{5}$ \\ Universitas Indraprasta PGRI \\ *E-mail: afanharis@ymail.com
}

\begin{tabular}{|c|c|}
\hline Info Artikel & Abstract \\
\hline $\begin{array}{l}\text { Sejarah Artikel: } \\
\text { Diterima Mei } 2019 \\
\text { Disetujui June } 2017 \\
\text { Dipublikasikan July } 2017 \\
\text { Keywords: } \\
\text { alat pembuka pintu portal, arduino, } \\
\text { smartphone }\end{array}$ & $\begin{array}{l}\text { This study aims to design a prototype Arduino-based portal door controller } \\
\text { system device using a smartphone. The making of the tool is done as one of } \\
\text { the efforts in advancing technology to provide convenience and comfort } \\
\text { through the development of an automated system in the home in the form } \\
\text { of automatic portal doors using smartphones. The components used for } \\
\text { system design are Arduino REV3 microcontroller module, USB } 2.0 \text { type A } \\
\text { / B cable (Arduino USB cable), SG90 9g servo motor, red and green } \\
\text { LEDs, } 220 \Omega \text { resistor, mini protoboard, connecting cable, jumper cable, and } \\
\text { bluetooth module HC06, Powerbank with a capacity of } 5600 \text { mAh and a } \\
\text { smartphone, while designing software uses Arduino IDE. Based on the } \\
\text { results of measurements and testing, the system on the device made is able } \\
\text { to open and close the portal door automatically at a maximum distance of } \\
15 \text { meters with a maximum response time of } 1 \text { second in open space }\end{array}$ \\
\hline
\end{tabular}

How to Cite: Afandi, A.H., Ghalia, P. A., Kistiani, Sari, I. R., Miza, S. A. (2019). Rancang Bangun Alat Pembuka Pintu Portal Berbasis Arduino Menggunakan Smartphone, Navigation Physics, 1 (1), 27-31.

\section{PENDAHULUAN}

Perkembangan dunia teknologi di dunia semakin hari semakin pesat, smartphone sudah hampir dimiliki semua orang di setiap rumah, bahkan dalam satu rumah hampir semua anggota memiliki smartphone. Mayoritas smartphone yang dimiliki hanya digunakan untuk hal - hal biasa, seperti menelepon, kirim pesan, dan aktivitas media sosial. Padahal smartphone pun dapat digunakan untuk keperluan pengontrolan sistem perangkat di dalam rumah. Salah satu usaha untuk memberikan kemudahan dan kenyamanan tersebut adalah melalui pengembangan sistem otomasi pada pengunci portal rumah (pintu gerbang rumah), yaitu sistem yang dapat membuka dan menutup pintu gerbang rumah dengan smartphone. Saat ini membuka dan menutup pintu gerbang masih menggunakan cara manual, dengan cara manual tentu masih memerlukan usaha secara lebih untuk melakukannya.

Penggunaan buka tutup gerbang rumah secara manual atau konvensional kurang praktis pada zaman sekarang karena pemilik rumah harus membawa kunci tersebut jika berpergian dari rumah dan sering kali pemilik rumah lupa bahkan kehilangan kunci. Dengan berkembangnya teknologi mikrokontroler saat ini, sistem keamanan dapat dilakukan dengan menggunakan alat elektronik sebagai pengganti sistem keamanan kunci konvensional. Hal ini juga berfungsi agar mengurangi tindak kejahatan pencurian yang sekarang sedang marak di masyarakat khususnya di daerah perumahan. Dengan menggunakan smartphone berbasis bluetooth untuk akses masuk ke dalam rumah, pencuri tidak akan bisa masuk ke dalam rumah dikarenakan tidak memiliki akses kontrol atau sistem pengendali.

Berdasarkan perkembangan teknologi khusususnya bidang elektronika telekomunikasi dan industri, terdapat suatu sistem mikrokontroler terbaru yaitu Arduino Uno. Arduino Uno merupakan salah satu development kit mikrokontroler yang berbasis pada ATmega28. Arduino Uno memiliki 14 kaki digital input / output, dimana 6 kaki digital diantaranya dapat digunakan sebagai sinyal PWM (Pulse 
Width Modulation). Sinyal PWM berfungsi untuk mengatur kecepatan perputaran motor. Arduino Uno memiliki 6 kaki analog input, kristal osilator dengan kecepatan jam $16 \mathrm{MHz}$, sebuah koneksi USB, sebuah konektor listrik, sebuah kaki header dari ICSP, dan sebuah tombol reset yang berfungsi untuk mengulang program (Magdalena dkk, 2013).

Kelebihan Arduino diantaranya adalah tidak perlu perangkat chip programmer karena didalamnya sudah ada bootloader yang akan menangani upload program dari komputer, Arduino sudah memiliki sarana komunikasi USB, sehingga pengguna laptop yang tidak memiliki port serial/RS323 bisa menggunakannya. Bahasa pemrograman relatif mudah karena software Arduino dilengkapi dengan kumpulan library yang cukup lengkap, dan Arduino memiliki modul siap pakai (shield) yang bisa ditancapkan pada board Arduino. Misalnya shield GPS, Ethernet, SD Card, dan lain-lain (Wibowo dkk, 2013). Arduino Uno yang dapat dimanfaatkan untuk dihubungkan dengan smartphone Android melalui bluetooth. Bluetooth merupakan sebuah teknologi komunikasi wireless yang beroperasi pada pita frekuensi 2,4 - 2,83 GHz unlicensed ISM (Industrial, Scientific and Medical). Bluetooth mampu menyediakan layanan komunikasi data antara host-host bluetooth dengan jarak jangkauan layanan yang terbatas.

\section{METODE PENELITIAN}

Alat dan bahan yang diperlukan dalam membuat alat ini adalah Arduino REV3, USB 2.0 tipe kabel

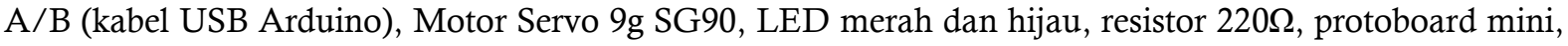
kabel penghubung, kabel jumper, smartphone, dan modul bluetooth HC06. Tahap pelaksanaan dari penelitian ini terdiri dari tahap persiapan, tahap perancangan desain sistem, tahap pembuatan alat, tahap pengujian, tahap penerapan, dan tahap evaluasi.

Pada tahap persiapan yang dilakukan yaitu adalah menyiapkan alat dan bahan yang dibutuhkan untuk menunjang pembuatan modul arduino uno dan perancangan alat. Rancangan desain blok diagram sistem ini dijelaskan seperti pada gambar 1.

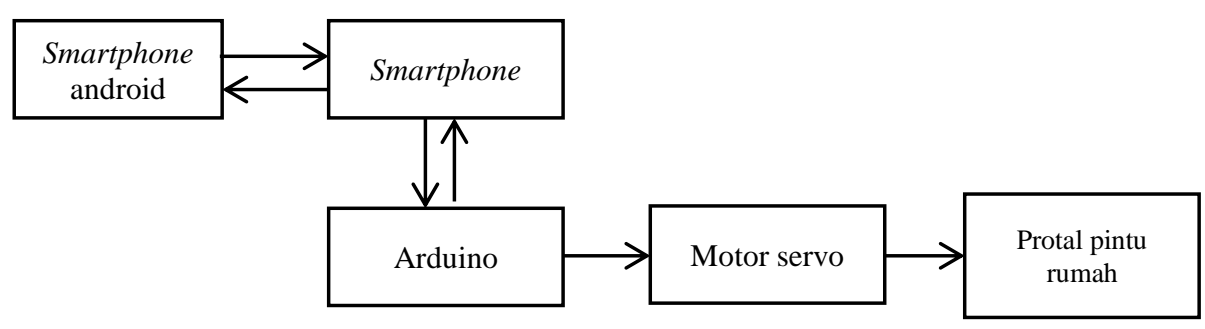

Gambar 1. Blok diagram sistem

Pembuatan alat dilakukan dalam tiga tahap yaitu meliputi pembuatan modul dari perangkat lunak, instalasi alat, dan finishing. Perangkat lunak yang dirancang ada 2 bagian, yaitu pada android dan board Arduino. Pada android menggunakan aplikasi bluetooth dengan nama remote gerbang. Pada Arduino, menggunakan Arduino IDE (Integrated Development Environment) dengan bahasa pemrograman C. Setelah modul selesai kemudian tahap perakitan alat. Setelah merangkai semua alat dan modul, langkah selanjutnya finishing. Finishing yaitu merapikan dan memperindah tampilan dari alat yang telah dibuat.

Pengujian dilakukan pada alat secara dua tahap. Pada tahap pertama pengujian dilakukan terhadap komponen pembentuk alat seperti motor servo, tegangan, dan bluetooth. Pengujian tahap kedua dilakukan terhadap komponen yang sudah dirangkai yang telah dirangkai menjadi satu - kesatuan dengan Modul dan menggunakan smartphone android dan bluetooth. Pada tahap ini dilihat apakah prototype berjalan dengan baik atau tidak. Pada tahap penerapan modul dan prototype yang sudah berhasil dibuat secara keseluruhan dan siap untuk diterapkan ke pintu rumah. Pada tahap evaluasi, tujuan dilakukannya untuk mengetahui ketercapaian tujuan dari program yang dilaksanakan, sehingga nantinya dapat dilakukan perbaikan dan pengembangan menjadi lebih baik lagi. 


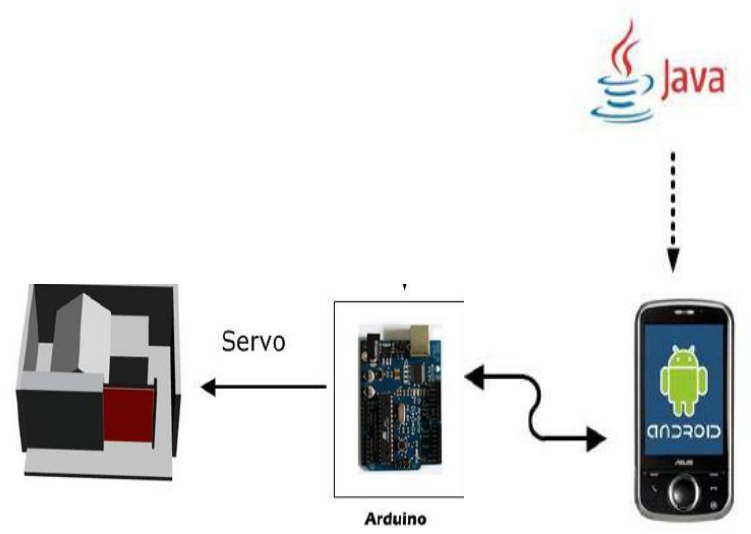

Gambar 2. Rancangan alat pembuka pintu portal berbasis arduino

\section{HASIL DAN PEMBAHASAN}

Arduino REV3 sebagai otak atau mikrokontroller yang berfungsi untuk memprogram alat ini sehingga bisa bekerja memerintahkan modul-modul lainnya dan tersambung ke koneksi smartphone yaitu bluetooth. Rangkaian komponen terdiri dari Arduino REV3, USB 2.0 tipe kabel A/B (kabel USB

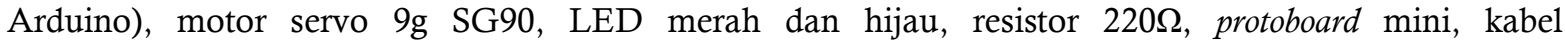
penghubung, kabel jumper, smartphone, dan modul bluetooth HC06. Rangkaian komponen dapat dilihat pada gambar 3 .

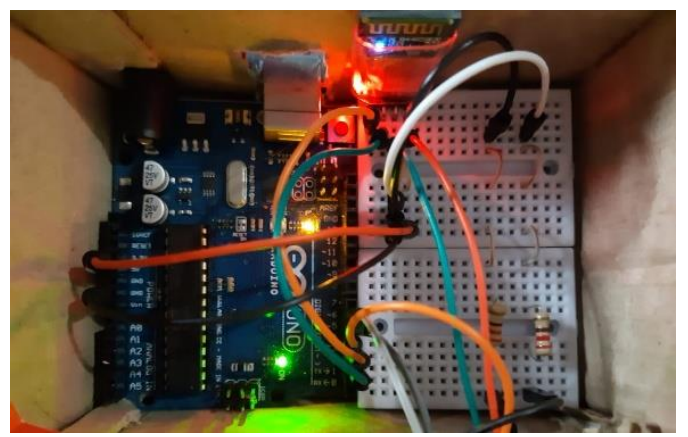

Gambar 3. Rangkaian komponen alat

Arduino REV3 membutuhkan sumber daya untuk bisa berfungsi ketika akan digunakan. Sumber daya yang digunakan dengan dihubungkan dengan powerbank menggunakan USB android. Setelah rangkaian komponen ahir dibuat, kemudian memasukkan koding di software arduino. Setelah dilakukan pengujian pada arduino maka langkah selanjutnya mendesain packaging dari alat pembuka pintu portal berbasis arduino. Tampilan akhir alat setelah dilakukan packaging dan testing untuk pembuktian alat tersebut dalam bentuk prototype yang dapat dilihat pada gambar 4 .

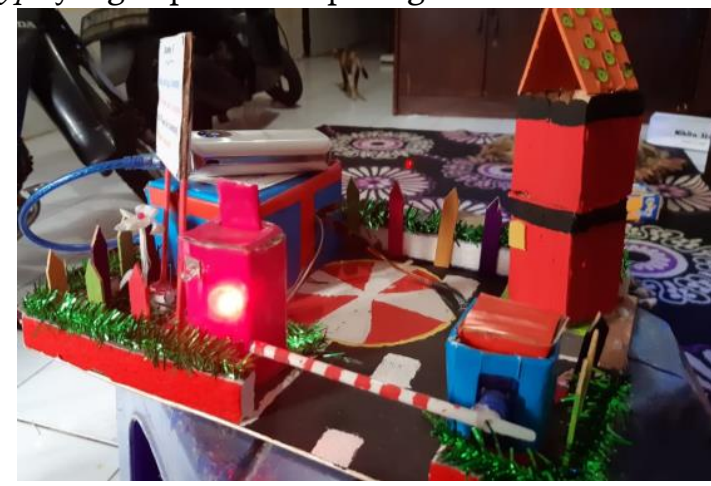

Gambar 4. Prototype alat pembuka pintu portal berbasis arduino

Prototype alat pembuka pintu portal berbasis arduino dengan menggunakan smartphone dibantu dengan aplikasi bluetooth. Bluetooth berfungsi untuk membuka perintak buka atau tutupnya portal dengan cara mengklik tombol ON pada aplikasi gerbang logika di smartphone. 


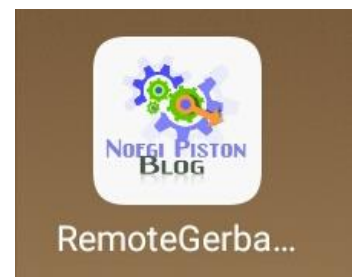

Gambar 5. Aplikasi remote gerbang

Ketika akan membuka pintu portal, terdapat motor servo yang yang bekerja untuk membuka atau menutup yang dihbungkan pada arduino, kemudian dengan proses perintah smartphone (menggunakan bluetooth) akan mampu membaca program dengan menekan tombol merah untuk membuka, dan tombol biru untuk menutup pintu portal.

\section{(3) Bluetooth}

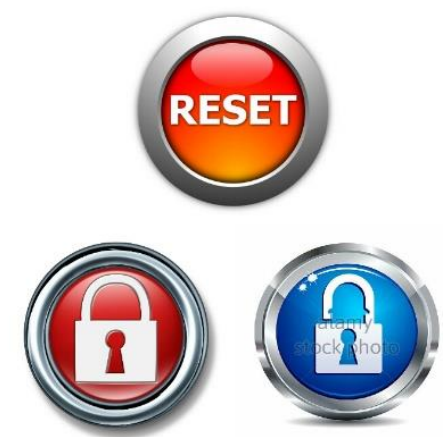

Gambar 6. Isi aplikasi gerbang logika pada smartphone

Alat pembuka pintu gerbang akan berkedip (lampu berwarna hijau) yang menandakan portal bisa terbuka kemudian ketika akan menutup lampu LED berwarna merah. Alat pembuka pintu portal dalam bentuk prototype ini mampu melaksanakan proses dalam maksimal 1 sekon, dan kemampuan membuka portalnya membutuhkan waktu 2 sekon. Alat tersebut berhasil digunakan sesuai fungsi dan tujuannya.

Tabel 1. Pengujian Koneksi Bluetooth

\begin{tabular}{cl}
\hline Jarak antara sistem bluetooth & \multicolumn{1}{c}{ Keterangan } \\
\hline 1 meter & Lancar menerima perintah \\
2 meter & Lancar menerima perintah \\
3 meter & Lancar menerima perintah \\
4 meter & Lancar menerima perintah \\
5 meter & Lancar menerima perintah \\
6 meter & Lancar menerima perintah \\
7 meter & Lancar menerima perintah \\
8 meter & Lancar menerima perintah \\
9 meter & Lancar menerima perintah \\
10 meter & Lancar menerima perintah \\
11 meter & Lancar menerima perintah \\
12 meter & Lancar menerima perintah \\
13 meter & Lancar menerima perintah \\
14 meter & Lancar menerima perintah \\
15 meter & Lancar menerima perintah \\
16 meter & Koneksi mulai tidak stabil \\
\hline
\end{tabular}

Alat yang dibuat mampu membuka dan menutup pintu portal secara otomatis pada jarak maksimum 15 meter dengan waktu respon maksimum 1 detik dalam keadaan ruang terbuka. Ketika mencapai jarak 16 meter koneksi mulai tidak stabil. Ini dikarenakan sistem program hanya mampu membaca pada jangkauan 15 meter. Alat ini mampu digunakan untuk mencegah tindak kejahatan pencurian di rumah karena sistem yang dibuat dijaga keamanannya dan tidak semua orang yang masuk ke rumah bisa mengakses. 


\section{PENUTUP}

Berdasarkan hasil dan pembahasan, diperoleh kesimpulan bahwa alat pembuka pintu gerbang berbasis arduino menggunkan smartphone berhasil dibuat dan digunakan sesuai fungsinya. Alat tersebut mampu dimanfaatkan untuk keamanan rumah dan dapat dibuat dalam skala besar. Alat yang dibuat sekarang masih dalam bentuk prototype, sehingga bisa dikembangkan lagi agar alat lebih efektif digunakan.

\section{DAFTAR PUSTAKA}

Guntoro, H., \& Somantri, Y. (2016). Rancang bangun magnetic door lock menggunakan keypad dan solenoid berbasis mikrokontroler arduino uno. electrans, 12(1), 39-48.

Magdalena, G., Aribowo, A., \& Halim, F. (2013). Perancangan Sistem Akses Pintu Garasi Otomatis. In Proceedings Conference on Smart-Green Technology in Electrical and Information System (pp. 301-205).

Mayasari, Hesti, SE, MM. (2012). Analisa Perilaku Pembelian Ponsel Cerdas (Smartphone) : Antara Kebutuhan dan Gaya Hidup Konsumen Di Kota Padang. Jurnal Manajemen dan KewirausahaanUniversitas Tamansiswa. Vol. 3. No. (1). 93-120.

Limantara, A. D., Purnomo, Y. C. S., \& Mudjanarko, S. W. (2017). Pemodelan Sistem Pelacakan Lot Parkir Kosong Berbasis Sensor Ultrasonic dan Internet of Things (IoT) Pada Lahan Parkir Diluar Jalan. Prosiding Semnastek.

Potts, J., \& Sukittanon, S. (2012). Exploiting Bluetooth on Android mobile devices for home security application. In Southeastcon, 2012 Proceedings of IEEE (pp. 1-4). IEEE.

Silvia, A. F., Haritman, E., \& Mulyadi, Y. (2014). Rancang Bangun Akses Kontrol Pintu Gerbang Berbasis Arduino Dan Android. Electrans, 13(1), 1-10.

Sunandar, E., Tiara, K., \& Daud, M. (2016). System Lock And Controlling Class Room dengan Interface Android Berbasis Arduino Uno. CCIT Journal, 9(2), 157-167. 